\title{
Pendidikan Kesehatan Tentang Manajemen Kesehatan Menstruasi Terhadap Pengetahuan dan Sikap Remaja Madrasah Tsanawiyah Swasta Amal Saleh
}

\author{
Nur Asnah Sitohang ${ }^{1, *}$, Dewi Elizadiani Suza ${ }^{2}$, Cut Adeya Adella ${ }^{3}$ \\ ${ }^{1}$ Universitas Sumatera Utara, Fakultas Keperawatan, Jl. Prof. T. Maas No. 3, Medan, Sumatera Utara 20155, Indonesia \\ ${ }^{2}$ Universitas Sumatera Utara, Fakultas Keperawatan, Jl. Prof. T. Maas No. 3, Medan, Sumatera Utara 20155, Indonesia \\ ${ }^{3}$ Universitas Sumatera Utara, Fakultas Kedokteran, Jl. Dr. Mansyur No. 5, Medan, Sumatera Utara 20155, Indonesia \\ 1Email: sitohangnurasnah@gmail.com *; ${ }^{2}$ Email : elizadiani@ hotmail.com, ${ }^{3}$ Email : cutadeya_adella@ gmail.com \\ * corresponding author
}

ARTICLE INFO

Keywords

Menstrual health management,

Adolescents,

Knowledge,

Attitudes

\section{ABSTRACT}

Menstruation is periodic bleeding occurring repeatedly every month in women that starts about 14 days after ovulation and is released through the vagina. Menstruation is a characteristic feature of a woman's maturity where there is a change in the uterus in preparation for pregnancy. Menstrual health management (MHM) is a term that is often used in relation to cleanliness during menstruation. Menstrual health management includes facilities used during menstruation including clean water, soap used for bathing and cleaning all parts of the body as well as cleaning sanitary napkins that have been used. MHM is also related to the access they have to safe and comfortable facilities to dispose of used sanitary napkins. Young women must understand knowledge about menstruation and how to manage it appropriately without shame or fear. Health education is a form of independent nursing action to help clients, both individuals, groups and communities in overcoming their health problems through learning activities in which the nurse acts as a nurse educator. This study aims to increase students' knowledge and attitudes about menstrual health management by providing health education. The method used was to socialize activities to the school, identify the condition of menstrual health service facilities in schools such as bathrooms, clean water supply, provide educational media for menstrual health management in the form of videos, leaflets and modules; conduct health education about menstrual health management and post tests. The data analysis used was univariate. The number of samples was 36 people, namely grade VII students. The results of the study that the majority of respondents were 12 years (77.8\%), had menstruation (58.3\%), age at first menstruation was 11 years $(52.3 \%)$, experienced menstrual pain $(66.7 \%)$, information sources regarding: (1) hygiene during menstruation is the mother $(38.5 \%)$, (2) sanitary napkins from TV commercials (25\%), menstruation from mothers (45.5\%), (3) types of sanitary napkins currently used modern sanitary napkins $(65.9 \%)$, (4) the current brand of sanitary napkins from mothers $(36.5 \%)$. The majority of knowledge adolescents category is $88.9 \%$ good and the attitude of the adolescents is $100 \%$ positive. Research proves that there are still students with sufficient knowledge $(10.1 \%)$ and considering the importance of MHM as an effort to prevent infection in the female reproductive system and minimize the occurrence of cervical cancer in women in the future. Researchers suggest that schools include this topic in subject matter so that reproductive health can be maintained.

\section{Pendahuluan}

Menstruasi adalah perdarahan periodik terjadi secara berulang setiap bulan pada uterus yang dimulai sekitar 14 hari setelah ovulasi dan keluar melalui vagina. Menstruasi merupakan ciri khas kedewasaan seorang perempuan dimana terjadi perubahan dari alat kandungan sebagai persiapan untuk kehamilan. Proses perubahan tersebut merupakan suatu hal yang kompleks, saling mempengaruhi dan bekerja sama antara korteks selebri, hipotalamus, dan ovarium (indung telur) serta dipengaruh olehglandula tyroidea, korteks adrenal [1]. Kesehatan menstruasi merupakan aspek yang sangat penting dalam membangun kualitas sumber daya manusia yang berkaitan 
dengan kesehatan reproduksi. Masalah tentang menstruasi dianggap kurang layak untuk dibahas di area publik serta kurang mendapat perhatian untuk dipelajari dan diajarkan, khususnya kepada perempuan. Hal tersebut yang menjadikan penyebab masih tersebarnya persepsi yang salah berkaitan dengan menstruasi [10].

Manajemen kesehatan menstruasi (MKM) merupakan istilah yang sering digunakan mencakup terkait kebersihan yang dilakukan saat menstruasi. Remaja perempuan harus menggunakan bahan pembalut yang bersih, aman untuk menyerap darah menstruasi dan menggantinya setiap empat jam. Manajemen kesehatan menstruasi juga mencakup fasilitas yang digunakan saat menstruasi meliputi air bersih dan sabun yang digunakan untuk mandi membersihkan seluruh bagian tubuh, membersihkan pembalut yang sudah selesai digunakan. MKM juga terkait dengan akses yang dimiliki ke fasilitas yang aman dan nyaman untuk membuang sampah pembalut yang telah digunakan. Remaja putri harus memahami pengetahuan tentang menstruasi dan bagaimana mengelolanya dengan tepat tanpa rasa malu ataupun takut [12].

Kesimpulannya Manajemen Kesehatan Menstruasi (MKM) merupakan pengelolaan kebersihan dan kesehatan pada saat perempuan mengalami menstruasi. Perempuan pun harus dapat menggunakan pembalut yang bersih, dapat diganti sesering mungkin selama periode menstruasi, dan memiliki akses untuk pembuangannya, serta dapat mengakses toilet, sabun, dan air untuk membersihkan diri dalam kondisi nyaman dengan privasi yang terjaga.

Penelitian di Uganda diperoleh data 90,5\% anak perempuan mengatakan mereka tidak memiliki fasilitas MKM yang baik, hal tersebut menyebabkan timbulnya rasa malu, tidak berani berdiri di kelas untuk menjawab pertanyaan atau berpartisipasi dalam kegiatan dan mereka khawatir tentang bau yang ditimbulkan dari menstruasi [5]. Penelitian di SMA Etislandia Medan tentang perilaku remaja putri dengan personal hygiene dengan jumlah siswi 45 orang, melalui wawancara kepada 7 orang siswi diperoleh data empat orang siswi mengatakan bahwa mereka mengalami rasa gatal pada area kemaluan, tiga diantaranya mengalami keputihan. Mayoritas responden tidak melakukan tindakan personal hygiene (60\%). Penelitian ini menunjukkan masih kurangnya pengetahuan remaja tentang praktik kebersihan menstruasi. Praktik kebersihan saat menstruasi pada remaja perlu diperhatikan [9].

Pengetahuan yang tidak sesuai, serta batasan-batasan yang dialami terkait dengan menstruasi dapat berdampak pada kesehatan, pendidikan maupun psikososial [16]. Praktik kebersihan saat menstruasi yang buruk menyebabkan remaja beresiko 1,4 sampai 25,07 kali terkena Infeksi Saluran Reproduksi (ISR) [15]. Perempuan 10\% terkena infeksi genital termasuk infeksi saluran kemih dan vaginitis bakteridi seluruh dunia setiap tahun. Perempuan juga $75 \%$ wanita memiliki riwayat infeksi genitaldi dunia. Faktor risiko umum infeksi vagina yaitu kehamilan dan kebersihan terkait perilaku yang buruk saat menstruasi [3].

Pokok permasalahan pada remaja terkait menstruasi ini adalah kurangnya pengetahuan mengenai MKM dan buruknya sanitasi air. Remaja putri banyak tidak memiliki pemahaman yang tepat bahwa menstruasi adalah proses biologis yang normal. Mereka justru baru mengenalnya pada saat menarche yaitu saat pertama kali mengalami menstruasi. Remaja putri juga sering kesulitan membeli atau mendapatkan pembalut saat diperlukan. Penelitian UNICEF di Indonesia pada 2015 menemukan fakta 1 dari 6 anak perempuan terpaksa tidak masuk sekolah selama satu hari atau lebih, pada saat menstrua. WHO menjelaskan kanker serviks merupakan kanker nomor dua terbanyak pada perempuan berusia 15-45 tahun setelah kanker payudara. Tidak kurang dari 500.000 kasus baru dengan kematian 280.000 penderita terjadi setiap tahun di seluruh dunia. Indonesia berada pada peringkat pertama untuk kasus wanita penderita kanker serviks sedunia, sedangkan data dari Yayasan Kanker Indonesia, bahwa kanker serviks mengakibatkan korban 
meninggal dunia sedikitnya 555 wanita perharinya dan 200.000 wanita pertahunnya. Pendidikan kesehatan merupakan suatu bentuk tindakan mandiri keperawatan untuk membantu klien baik individu, kelompok, maupun masyarakat dalam mengatasi masalah kesehatannya melalui kegiatan pembelajaran yang didalamnya perawat sebagai perawat pendidik [14].

\section{Metode}

Metode yang digunakan adalah diawali melakukan sosialisasi kegiatankepada pihak sekolah, mengidentifikasi keadaan fasilitas pelayanan manajemen kesehatan menstruasi seperti kamar mandi dan penyediaan air bersih. Selanjutnya dilakukan pendidikan kesehatan kepada responden kelas VII sebanyak 36 orang, menggunakan media edukasi video, leaflet dan modul. Tehnik pengambilan sampel adalah total sampling. Alasan pemilihan sampel hanya kelas VII karena kegiatan ini dilakukan pada masa pandemi covid 19 sehingga pihak sekolah hanya mengizinkan siswa kelas VII untuk mengikuti kegiatan dengan mematuhi protokol covid 19. Post testdilakukan setelah pelaksanaan pendidikan kesehatan.Tujuannya untuk mengidentifikasi pengetahuan dan sikap remaja tentang manajemen kesehatanmenstruasi. Analisis data yang digunakan adalah univariat distribusi frekwensi.

\section{Hasil dan Diskusi}

Tabel 1. Distribusi Frekwensi karakteristik responden di MTS Swasta Amal Saleh (n= 36)

\begin{tabular}{l|c|c}
\hline \multicolumn{1}{c|}{ Variabel } & F & \% \\
\hline Usia & 5 & 13,9 \\
- 11Tahun & 28 & 77,8 \\
- 12Tahun & 2 & 5,6 \\
- 13Tahun & 5 & 2.8 \\
- 14Tahun & & \\
\hline Apakah sudah haid/menstruasi ? & 15 & 41,7 \\
- Belum & 21 & 58,3 \\
- Sudah & 11 & 52,3 \\
\hline Usia pertama kali mendapat menstruasi ? & 9 & 43 \\
- 11Tahun & 1 & 4,7 \\
- 12Tahun & & \\
- 13Tahun & & \\
\hline Apakah pernah mengalami nyeri haid ? & 14 & 66,7 \\
- Ya & 7 & 33,3 \\
- Tidak & & \\
\hline Jika mengalami nyeri haid apa yang dilakukan ? & 14 & 34,1 \\
- Istirahat & 11 & 26,8 \\
- Minum airhangat & 3 & 7,3 \\
- Minumjamu & 2 & 4,9 \\
- Bermaingame & & 26,8 \\
- Tidakada & &
\end{tabular}


Tabel 2. Distribusi frekwensi sumber informasi yang didapat responden tentang manajemen kesehatan menstruasi $(n=36)$

\begin{tabular}{|c|c|c|c|}
\hline No & Pertanyaan & $\mathbf{F}$ & $\%$ \\
\hline 1 & $\begin{array}{l}\text { Sumber informasi mengenai kebersihan diri kewanitaan pada saat } \\
\text { menstruasi: } \\
\text { Iklan di TV } \\
\text { Ayah } \\
\text { Ibu } \\
\text { Kakak } \\
\text { Guru } \\
\text { Media cetak } \\
\text { Teman }\end{array}$ & $\begin{array}{c}4 \\
0 \\
25 \\
9 \\
15 \\
1 \\
11\end{array}$ & $\begin{array}{c}6,2 \\
0 \\
38,5 \\
13,8 \\
23,1 \\
1,5 \\
16,9\end{array}$ \\
\hline 2 & $\begin{array}{l}\text { Sumber informasi mengenai pembalut : Iklan di TV } \\
\text { Ayah } \\
\text { Ibu } \\
\text { Kakak } \\
\text { Guru } \\
\text { Media cetak } \\
\text { Teman }\end{array}$ & $\begin{array}{c}15 \\
0 \\
19 \\
7 \\
7 \\
2 \\
10\end{array}$ & $\begin{array}{c}25 \\
0 \\
31 \\
11,7 \\
11,7 \\
3,3 \\
16,7\end{array}$ \\
\hline 3 & $\begin{array}{l}\text { Sumber informasi menstruasi : Iklan di } \\
\text { TV } \\
\text { Ayah } \\
\text { Ibu } \\
\text { Kakak } \\
\text { Guru } \\
\text { Media cetak } \\
\text { Teman }\end{array}$ & $\begin{array}{c}2 \\
0 \\
25 \\
5 \\
11 \\
2 \\
10\end{array}$ & $\begin{array}{c}3,6 \\
0 \\
45,5 \\
9,1 \\
20 \\
3,6 \\
18,2\end{array}$ \\
\hline 4 & $\begin{array}{l}\text { Jenis pembalut yang digunakan saat ini : Pembalut } \\
\text { tradisional/kain } \\
\text { Pembalut modern }\end{array}$ & $\begin{array}{l}14 \\
27\end{array}$ & $\begin{array}{l}34,1 \\
65,9\end{array}$ \\
\hline 5 & $\begin{array}{l}\text { Di Sumber informasi terkait merk pembalut yang digunakan sekarang: } \\
\text { Iklan di TV } \\
\text { Ayah } \\
\text { Ibu } \\
\text { Kakak } \\
\text { Guru } \\
\text { Media cetak } \\
\text { Teman }\end{array}$ & $\begin{array}{c}18 \\
0 \\
19 \\
4 \\
4 \\
2 \\
5\end{array}$ & $\begin{array}{c}34,6 \\
0 \\
36,5 \\
7,7 \\
7,7 \\
3,8 \\
9,6\end{array}$ \\
\hline
\end{tabular}


Tabel 3. Distribusi frekwensi isi kuesioner pengetahuan siswa MTS Swasta Amal Saleh $(n=36)$

\begin{tabular}{|c|c|c|c|c|c|c|c|}
\hline \multirow[t]{2}{*}{ No } & \multirow[t]{2}{*}{ Pernyataan } & \multicolumn{2}{|c|}{ Benar } & \multicolumn{2}{|c|}{ Salah } & \multicolumn{2}{|c|}{$\begin{array}{r}\text { Tidak } \\
\text { tahu }\end{array}$} \\
\hline & & $\mathrm{F}$ & $\%$ & $\mathrm{~F}$ & $\%$ & $\mathrm{~F}$ & $\%$ \\
\hline 1 & $\begin{array}{l}\text { Menstrusasi adalah proses yang dialami semua perempuan untuk } \\
\text { menjadi dewasa ditandai dengan keluarnya darah disebabkan aktifnya } \\
\text { alat reproduksi sehingga siap menjadi ibu }\end{array}$ & 30 & 83,3 & 4 & 11,1 & 2 & 5,6 \\
\hline 2 & Menstruasi adalah proses yang nrmal pada wanita & 32 & 88,9 & 3 & 8,3 & 1 & 2,8 \\
\hline 3 & $\begin{array}{l}\text { Manajemen kesehatan menstruasi adalah kebersihan diri seorang wanita } \\
\text { ketika menstruasi }\end{array}$ & 31 & 86,1 & 1 & 2,8 & 4 & 11,1 \\
\hline 4 & $\begin{array}{l}\text { Tujuan manajemen kesehatan menstruasi adalah mencegah penyakit dan } \\
\text { meningkatkan perasaan sejahtera }\end{array}$ & 28 & 77,8 & 3 & 8,3 & 5 & 13,9 \\
\hline 5 & Darah menstruasi keluar dari vagina (kemaluaan) & 35 & 97,2 & 0 & 0 & 1 & 2,8 \\
\hline 6 & $\begin{array}{l}\text { Siklus menstruasi adalah waktu sejak hari pert } \\
\text { datangnya menstruasi periode berikutnya }\end{array}$ & 24 & 66,7 & 5 & 13,9 & 7 & 19,4 \\
\hline 7 & Siklus & 11 & 30,6 & 18 & 50,0 & 7 & 19,4 \\
\hline 8 & Siklus & 18 & 50,0 & 8 & 22,2 & 10 & 27,8 \\
\hline 9 & Lama & 35 & 97,2 & 1 & 2,8 & 0 & 0 \\
\hline 10 & ruasi pertama & 30 & 83,3 & 4 & 11,1 & 2 & 5,6 \\
\hline 11 & $\begin{array}{l}\text { Pemba } \\
\text { agar ti }\end{array}$ & 34 & 94,4 & 1 & 2,8 & 1 & 2,8 \\
\hline 12 & Pembalut ada du & 35 & 97,2 & 1 & 2,8 & 0 & 0 \\
\hline 13 & $S$ & 35 & 97,2 & 1 & 2,8 & 0 & 0 \\
\hline 14 & emba & 34 & 94,4 & 1 & 2,8 & 1 & 2,8 \\
\hline 15 & $\begin{array}{l}\text { dengan kertas koran/kertas } \\
\text { pah }\end{array}$ & 32 & 88,9 & 4 & 11,1 & 0 & 0 \\
\hline 16 & dengan sabun dan dibilas dengan air bersih & 34 & 94,4 & 1 & 2,8 & 1 & 2,8 \\
\hline 17 & $\begin{array}{l}\text { h dibilas dengan air panas karena bisa } \\
\text { ja }\end{array}$ & 15 & 41,7 & 14 & 11,1 & 17 & 47,2 \\
\hline 18 & ah dinakai herkali-kali harus dibuano & 22 & 61,1 & 10 & 27,8 & 4 & 11,1 \\
\hline 19 & $\begin{array}{l}\text { Menj } \\
\text { seper }\end{array}$ & 31 & 86,1 & 4 & 11,1 & 1 & 2,8 \\
\hline 20 & Saat menstruasi, tubuh $\mathrm{h}$ & 34 & 94,4 & 1 & 2,8 & 1 & 2,8 \\
\hline 21 & $\begin{array}{l}\text { Perubahan suasana } 1 \\
\text { kimia dalam tubuh }\end{array}$ & 29 & 80,8 & 1 & 2,8 & 6 & 16,7 \\
\hline 22 & Bero & 8 & 22,2 & 23 & 63,9 & 5 & 13,9 \\
\hline 23 & Jika s & 14 & 38,9 & 14 & 38,9 & 8 & 22,2 \\
\hline 24 & Dishm & 24 & 66,7 & 3 & 8,3 & 9 & 25 \\
\hline 25 & Pakaian dalam (celana dalam) harus & 32 & 88,9 & 1 & 2,8 & 3 & 8,3 \\
\hline 26 & $\begin{array}{l}\text { Kram perut (nyeri) pada saat menstruasi dapat dikurangi dengan tidur } \\
\text { telentang dan kompres air hangat }\end{array}$ & 27 & 75,0 & 2 & 5,6 & 7 & 19,4 \\
\hline 27 & $\begin{array}{l}\text { Rasa pusing saat menstruasi dapat diatasi dengan banyak minum air } \\
\text { putih danistirahat }\end{array}$ & 33 & 91,7 & 1 & 2,8 & 2 & ,6 \\
\hline 28 & $\begin{array}{l}\text { Kembung perut dapat diatasi dengan minum air hangat dan banyak } \\
\text { makan sayur/buah }\end{array}$ & 34 & 94,4 & 1 & 2,8 & 1 & 8 \\
\hline 29 & Jika merasa nyeri saat menstru & 33 & 91,7 & 3 & 8,3 & 0 & 0 \\
\hline 30 & Jika sedang menstruasi dilarang sekolah & 1 & 2,8 & 34 & 94,4 & 1 & 2,8 \\
\hline
\end{tabular}


Tabel 4. Distribusi frekuensi katogeri pengetahuan siswa MTS Swasta Amal Saleh (n=36)

\begin{tabular}{llc} 
Variabel & F & \% \\
\hline Baik & 32 & 88,9 \\
Cukup & 4 & 11,1 \\
\hline
\end{tabular}

Tabel 5. Distribusi frekuensi isi kuesioner sikap siswa MTS Swasta Amal Saleh $(n=36)$

\begin{tabular}{|c|c|c|c|c|c|c|c|}
\hline \multirow[t]{2}{*}{ No } & \multirow[t]{2}{*}{ Pernyataan } & \multicolumn{2}{|c|}{ Setuju } & \multicolumn{2}{|c|}{ Ragu-ragu } & \multicolumn{2}{|c|}{$\begin{array}{l}\text { Tidak } \\
\text { setuju }\end{array}$} \\
\hline & & $\mathbf{F}$ & $\%$ & $\mathbf{F}$ & $\%$ & $\mathbf{F}$ & $\%$ \\
\hline 1 & Saya mandi 2 kali sehari saat menstruasi & 32 & 88,9 & 1 & 2,8 & 3 & 8,3 \\
\hline 2 & $\begin{array}{l}\text { Saya akan mencuci rambut (keramas) } 3 \text { kali dalam } \\
\text { seminggu saat menstruasi }\end{array}$ & 23 & 63,9 & 7 & 19,4 & 6 & 16,7 \\
\hline 3 & $\begin{array}{l}\text { Saya akan mencuci tangan sebelum dan sesudah memakai } \\
\text { Pembalut }\end{array}$ & 35 & 97,2 & 1 & 2,8 & 0 & 0 \\
\hline 5 & $\begin{array}{l}\text { Saya akan membersihkan kemaluan dengan sabun dan } \\
\text { membilas dengan air bersih }\end{array}$ & 33 & 91,7 & 2 & 5,6 & 1 & 2,8 \\
\hline 6 & Saya akan mengganti pembalut 3-4 kali sehari & 29 & 80,6 & 4 & 11,1 & 3 & 8,3 \\
\hline 7 & $\begin{array}{l}\text { Saya akan segera mengganti celana dala yan dengan kertas } \\
\text { terkena darah menstruasi }\end{array}$ & 36 & 100 & 0 & 0 & 0 & 0 \\
\hline 8 & $\begin{array}{l}\text { Saya akan membungkus pembalut bekas pakai dengan } \\
\text { kertas/plastic sebelum dibuang ke tempat smapah }\end{array}$ & 36 & 100 & 0 & 0 & 0 & 0 \\
\hline 9 & $\begin{array}{l}\text { Saya akan memakai celana dalam dengan bahan katun } \\
\text { yang menyerap keringat }\end{array}$ & 18 & 50,0 & 13 & 36,1 & 5 & 13,9 \\
\hline 10 & $\begin{array}{l}\text { Jika masa haid lebih } 7 \text { hari saya akan melaporkan kepada } \\
\text { ibu saya }\end{array}$ & 33 & 91,7 & 3 & 8,3 & 0 & 0 \\
\hline 11 & Jika menstruasi saya akan bermalas-malasan saja & 1 & 2,8 & 4 & 11,1 & 31 & 86,1 \\
\hline 12 & $\begin{array}{l}\text { Jika rok sekolah saya terkena darah menstruasi akan saya } \\
\text { tutupi dengan tas sekolah atau kain }\end{array}$ & 36 & 100 & 0 & 0 & 0 & 0 \\
\hline 13 & $\begin{array}{l}\text { Jika perut saya tersa nyeri/kram menjelang dan selama haid } \\
\text { saya akan mengompres dengan air hangat }\end{array}$ & 29 & 80,6 & 2 & 5,6 & 5 & 13,9 \\
\hline 14 & $\begin{array}{l}\text { Selama menstruasi saya akan banyak minum dan makan } \\
\text { makanan bergizi }\end{array}$ & 34 & 94,4 & 1 & 2,8 & 1 & 2,8 \\
\hline 15 & Saya tidak akan membuang pembalut bekas ke lubang WC & 30 & 83,3 & 1 & 2,8 & 5 & 13,9 \\
\hline
\end{tabular}

Tabel 6. Distribusi frekuensi katogeri sikap siswa MTS Swasta Amal Saleh (n=36)

\begin{tabular}{ccc} 
Variabel & F & \% \\
\hline Positif & 100 & 100 \\
Negatif & 0 & 0 \\
\hline
\end{tabular}

\section{Pembahasan}

Hasil penelitian diperoleh data mayoritas responden 12 tahun $(77,8 \%)$, sudah menstruasi $(58,3 \%)$, usia pertama kali mendapat menstruasi 11 tahun $(52,3 \%)$, mengalami nyeri haid $(66,7 \%)$, Kategori pengetahuan siswa mayoritas baik $88.9 \%$. Masa remaja merupakan usia yang menjadi masa yang baik (menjadi suatu bentuk kesempatan) bagi anak-anak dan menjadi waktu yang sangat 
penting untuk membangun perkembangan mereka dalam dekade pertama kehidupan, membantu mereka dalam mencari jalan bagi risiko dan kerentanan, serta mengatur untuk memenuhi potensi mereka [16].

Pengetahuan merupakan hasil dari tahu, dan ini terjadi setelah orang melakukan pengindraan terhadap suatu objek tertentu. Pengindraan terjadi melalui panca indra manusia, yakni indra penglihatan, pendengaran, penciuman, rasa, dan raba. Sebagian besar pengtahuan manusia diperoleh melalui mata dan telinga. Pengetahuan atau ranah kognitif merupakan domain yang sangat penting dalam membentuk tindakan seseorang. Pengetahuan tentang manajemen kesehatan menstruasiakan mempengaruhi sikap dan dalam pelaksaannya. Pengetahuan yang baik dapat meningkatkan kesehatan [8]. Hasil penelitian diperoleh masih ada siswa tidak tahu bahwa siklus menstruasi tidak normal jika kurang 21 hari atau lebih 40 hari $(27,8 \%)$ dan pembalut kain tidak boleh dibilas dengan air panas karena bisa mengurangi daya serapnya $(47,2 \%)$.

Siklus menstruasi merupakan daur menstruasi yang tiap bulannya dialami wanita dihitung mulai dari hari pertama menstruasi atau datang bulan, sampai hari pertama menstruasi di bulan berikutnya. Menstruasi dikatakan normal bila didapati siklus mentruasi tidak kurang dari 24 hari, tetapi tidak melebihi 35 hari, kira-kira 24-35 hari dikatakan siklus menstruasi yang normal [7]. Pembalut kain merupakan potongan kain yang dapat digunakan kembali saat menstruasi. Kain ini menggunakan bahan yang lembut. Kain tidak bisa digunakan secara berulang lebih dari 1 tahun. Kain pembalut dibersihkan dengan cara pencucian dan pengeringan yang tepat agar penggunaan tetap aman [6].

Peneliti berpendapat tingkat pengetahuan responden yang berada pada kategori cukup dikarenakan masih kurangnya paparan informasi terkait manajemen kesehatan menstruasi. Hasil penelitian sumber informasi yang mereka peroleh mengenai : (1) kebersihan bagian kewanitaan pada saat menstruasi adalah ibu (38,5\%), (2) pembalut dari iklan diTV (25\%), menstruasi dari ibu $(45,5 \%)$, (3) jenis pembalut yang digunakan saat ini pembalutmodern $(65,9 \%)$, (4) merk pembalut yang digunakan sekarang dari ibu (36,5\%) dan tingkat pendidikan mereka juga masih kelas VII SMP dan tidak ada mempelajari topik ini di sekolah.

Tingkat pengetahuan seseorang dipengaruhi oleh tingkat pendidikan, pengalaman, usia, informasi, lingkungan budaya dan sosial ekonomi.Pendidikan kesehatan dapat meningkatkan pengetahuan siswa. Pendidikan kesehatan yang diberikan kepada remaja dapat meningkatkan pengetahuan dan sikapnya terhadap manajemen kesehatan menstruasi. Media pendidikan kesehatan yang digunakan efektif dalam meningkatkan pemahaman remaja. Pendidikan kesehatan adalah upaya persuasi atau pembelajaran kepada masyarakat agar masyarakat mau melakukan tindakantindakan untuk memelihara, dan meningkatkan taraf kesehatannya [8]. Pendidikan kesehatan adalah bentuk kegiatan dengan menyampaikan materi tentang kesehatan yang bertujuan untuk mengubah perilaku sasaran. Pendidikan kesehatan berpengaruh pada pengetahuan dan sikap siswa SMP Dharma Pancasila Medan (nilai $\mathrm{P}=0,001$ ). Media yang digunakan dalam penelitian ini adalah power ponit, video, leaflet dan modul. Metode pelaksanaan melakukan ceramah dan diskusi [15].

Sikap merupakan reaksi atau respon yang masih tertutup dari seseorang terhadap suatu stimulus atau objek. Manifestasi sikap itu tidak dapat langsung dilihat tetapi dapat ditafsirkan terlebih dahulu. Sikap manusia tidak terbentuk sejak manusia dilahirkan. Sikap manusia terbentuk melalui proses sosial yang terjadi selama hidupnya, dimana individu mendapatkan informasi dan pengalaman. Sikap merupakan sesuatu yang dipelajari dan menentukan bagaimana individu bereaksi terhadap situasi serta menentukan apa yang dicari oleh individu dalamhidupnya.Proses tersebut dapat berlangsung di dalam lingkungan keluarga, sekolah maupun masyarakat. Sikap 
belum merupakan suatu tindakan atau aktifitas akan tetapi merupakan predisposisi tindakan suatu perilaku [2].

Hasil penelitian diperoleh masih ada remaja yang tidak setuju mencuci rambut (keramas) 3 kali dalamseminggu saat menstruasi (16,7\%); memakai celana dalam dengan bahan katunyang menyerap keringat (13,9\%), tidak akan membuang pembalut bekas ke lubang WC (13,9\%). Sikap responden yang positif karena tingkat pengetahuan responden mayoritas baik (88,9\%). Sikap seorang individu sangat erat hubunganya dengan sikapnya masing-masing sebagai ciri pribadinya.

Sikap pada umumnya sering diartikan sebagai suatu tindakan yang dilakukan individu untuk memberikan tanggapan pada suatu hal. Komponen sikap mencakup tiga aspek yaitu, komponen kognitif, afektif dan konatif. Komponen kognitif berupa pemahaman, pengetahuan, pandangan dan keyakinan seseorang terhadap objek sikap. Komponen afektif yaitu perasaan senang atau tidak senang terhadap objek sikap. Komponen konatif yaitu kecenderungan bertindak terhadap objek sikap yang menunjukan intensitas sikap yaitu besar kecilnya intensitas bertindak atau berperilaku seseorang terhadap objeksikap [10].

Sikap atau attitude adalahsebagai suatu reaksi pandangan atau perasaan seorang individu terhadap objek tertentu. Sikap individu terhadap objek yang sama bisa berbeda. Sikap individu dipengaruhi oleh keadaan individu, pengalaman, informasi dan kebutuhan masing- masing individu. Sikap seseorang terhadap objek akan membentuk perilaku individu terhadap objek [4]. Sikap adalah suatu proses penilaian yang dilakukan oleh seorang individu terhadap suatu objek. Objek yang disikapiindividu dapat berupa benda, manusia atau informasi [10]. Proses yang mengawali terbentuknya sikap adalah adanya objek di sekitar individu berupa informasi dalam hal ini adalah manajemen kesehatan menstruasi.

Pendidikan kesehatan tentang manajemen kesehatan menstruasi memberikan stimulus kepada remaja. Informasi yang didapat kemudian diproses di dalam otak dan memunculkan suatu reaksi. Proses penilaian seorang terhadap suatu objek dapat berupa penilaian positif dan negatif. Penilaian yang muncul positif atau negatif dipengaruhi oleh informasi sebelumnya, atau pengalaman pribadi individu. Pengalaman terhadap suatu objek yang memberikan kesan menyenangkan atau baik akan membentuk sikap yang positif sedangkan pengalaman yang kurang menyenangkan akan membentuk sikap negatif. Sikap individu perlu diketahui arahnya negatif atau positif [4].

\section{Kesimpulan}

Penelitian membuktikan bahwa pengetahuan remaja tentang manajemen kesehatan menstruasi setelah mengikuti pendidikan kesehatan mayoritas baik (88.9\%) dan sikapnya semua positif. Saran kepada kepala sekolah agar melanjutkan kegiatan pemberian informasi ini kepada siswa dikelas lain dengan menggunakan media yang telah diberikan. Lebih baik jika memasukkan topik ini dalam mata pelajaran. 


\section{Ucapan Terima Kasih}

Hasil penelitian ini merupakan salah satu luaran pelaksanaan pengabdian kepada masyarakat dengan dana NON PNBP Universitas Sumatera Utara Sesuai dengan Surat Perjanjian Penugasan Pelaksanaan Pengabdian kepada Masyarakat Program Mono Tahun Reguler Tahun Anggaran 2020 Nomor : 287/UN5.2.3.2.1/PPM/2020, Tanggal 9 Juni 2020, untuk itu kami sampaikan terima kasih kepada bapak rektor, Wakil rektor III dan ketua LPPM USU.

\section{Referensi}

[1] Asrinah, dkk. (2011). Menstruasi dan Permasalahannya. Banjarnegara: Pustaka Panasea.

[2] Asriwati., I. (2019). Buku Ajar Antropologi Kesehatan dalam Keperawatan. Jakarta : Pendidikan Deepublish

[3] Geethu. (2016). Appraisal Of Management Health Menstruation Practice Among Women In A Rural Setting: A Prospectitive Study. International Journal Of Community Medicine And Public Health

[4] Gerungan. (2004). Psikologi Terapan. Bandung: Refika Aditama

[5] Hennegan, J. \& Montgomery, P. (2016). Menstruation and The Cycle of Poverty. A Cluster Quasi. NCBI. Journal in Uganda. www.ncbi.nml.gov.

[6] Kaur, R, Kaur, K, Kaur, R. (2017). Menstrual Hygiene, Management, And Waste Disposal: Practices And Challenges Faced By Girls/ Woman Of Developing Countries. India. Journal of Environmental and Publi Health.Vol 2018, Article ID 1730964, Diakses melalui https://doi.org/10.1155/2018/1730964. pada 15 Januari 2020.

[7] Kusmiran, E. (2011). Kesehatan Reproduksi Remaja \& Wanita. Jakarta : Salemba Medika

[8] Notoatmodjo. S. (2010). Teori Perilaku. Jakarta: Rineka Cipta.

[9] Pemiliana, P.D., Agustina, W., Verayanti, D. (2018). Perilaku Remaja Putri dengan Personal Hygienesaat Menstruasi di SMA Etidlandia Medan Tahun 2018. Vol 5. No 1 (12-24)

[10] Sarwono.SW., EA.Meinarmo. (2009). Psikologi Sosial. Jakarta : Salemba Humanika

[11] Sinaga, dkk.(2017). Manajemen kesehatan menstruasi. Jakarta. Global One.

[12] Sommer, M., Sutherland, C. Mouli V., C. (2015). Putting Menarche and Girls Into The Global Population Health Agenda. Reproductive Health.

[13] Suliha. (2002). Pendidikan Kesehatan dalam Keperawatan. Jakarta : EGC

[14] Sumpter, C., (2013). A Systematic Review of the Health and Social Effects of Menstrual Hygiene Management. Plos One8

[15] Sitohang.N., Adeyya.A.C. (2019). Pengaruh Pendidikan Kesehatan Terhadap Pengetahuan dan Sikap Siswa SMP Dharma Pancasila tentang Manajemen Kesehatan Menstruasi. Jurnal Riset Hesti Medan Akper KesdamI/BB Medan.Vol.4.No.2.Desember 2019 (126-130)

[16] Unicef. (2019). Guide To Menstrual Hygiene Materials. New York, NY 10017 USA. Diunduh melalui https://www.unicef.org. pada 23 Januari 2020. 